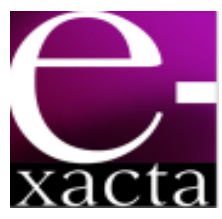

ISSN: 1984-3151

\title{
GESTÃo LEAN NA LINHA DE MONTAGEM DE UMA INDÚSTRIA MULTINACIONAL DO RAMO PETROLÍFERO
}

\author{
LEAN MANAGEMENT IN THE ASSEMBLY LINE OF A MULTINATIONAL \\ COMPANY OF OIL INDUSTRY
}

\author{
Paulo Bonafé ${ }^{1}$; Álvaro Azevedo Cardoso ${ }^{2}$ \\ 1 Mestrando do Departamento de Engenharia Mecânica da \\ Universidade de Taubaté - UNITAU. Taubaté - SP. \\ paulo.bonafe@c-a-m.com. \\ $2 \mathrm{PhD}$ em Engenharia Mecânica. University Of Southampton, \\ Grã-Bretanha. 1980. Professor do Departamento de \\ Engenharia Mecânica da Universidade de Taubaté - \\ UNITAU. Taubaté - SP. aazevedocardoso@gmail.com.
}

Recebido em: 14/10/2012 - Aprovado em: 20/11/2012 - Disponibilizado em: 30/11/2012

\begin{abstract}
RESUMO: No cenário atual do mercado petrolifero mundial, principalmente no Brasil, com a descoberta do Pré-Sal, as empresas buscam um diferencial competitivo, com intuito de absorverem a maior parcela deste mercado. A pesquisa é elaborada em uma empresa multinacional do ramo petrolífero e apresenta os passos da implementação da Gestão Lean, utilizando ferramentas como 5S, Mapa de Fluxo de Valor, Padronização e mudança de Layout, visando aumentar a capacidade produtiva a fim de atender às necessidades dos seus clientes, não perdendo mercado para as concorrentes. É apresentado um comparativo entre o estado atual, no qual o processo de montagem apresenta deficiências, e o estado futuro que revela os resultados obtidos na prática com a Gestão Lean. Localizada no Vale do Paraíba é uma das empresas líderes de mercado, especializada na fabricação, montagem e testes de equipamentos utilizados na prospecção de petróleo. Por meio das ferramentas Lean, foram possíveis mudanças como, Layout em Células, redução do tempo de processo em $33,33 \%$, redução do inventário de materiais, eliminação de desperdícios, que trouxe uma economia de aproximadamente $R \$ 300$ mil no mês de agosto de 2011, padronização das atividades e redução de não conformidades. Concluiu-se que o atendimento aos princípios Lean, viabiliza a ampliação do nível de competitividade da empresa, através de processos ágeis e flexíveis e com utilização otimizada de recursos.

PalAvRAS-Chave: Gestão Lean. 5S. Layout Celular. Padronização. Mapeamento do Fluxo de Valor. Lean Manufacturing.
\end{abstract}

ABSTRACT: In the current scenario of the world oil market, especially in Brazil, with the discovery of the Pré-Sal, companies seek for a competitive edge, aiming to absorb the largest share of this market. The research is designed in a multinational company of the oil industry and presents the steps of the implementation of Lean Management using tools like 5S, Value Stream Map, Standardization and Change of Layout in order to increase production capacity to meet the needs of their customers, not losing market share to competitors. It is presented a comparison between the current state in which the assembly process is flawed, and the future state that shows the results obtained in practice with the Lean Management. Located in the Vale Paraiba it is one of the market leaders specializing in the manufacture, assembly and testing of equipment used in oil exploration. Through the Lean Tools, such changes were possible, Cell Layout, reducing the process time in $33.33 \%$, reduction in inventory of materials, waste disposal, which brought a savings of approximately $R \$ 300.000$ in August 2011, Standardization of activities and reduction of nonconformities. It was concluded a attendance of Lean principles, enables the expansion of the level of competitiveness of the company, trough agile and flexible and optimized use of resources. KEYWORDS: Lean Management, 5S, Layout Cell, Standardization, Value Stream Map, Lean Manufacturing. 


\section{INTRODUÇÃo}

Devido à crescente exponencial do mercado petrolífero no mundo e principalmente no Brasil, atingir as margens de lucro estabelecidas pelas empresas, está sendo uma meta cada vez mais desafiadora, pois a concorrência vem aumentando dia-a-dia.

O presente trabalho tem como objetivo apresentar 0 processo de implementação da Gestão Lean em uma linha de montagem final de uma empresa multinacional do ramo petrolífero, a fim de obter eficiência operacional e consequentemente um diferencial no mercado, mostrando um comparativo entre o estado atual, no qual o processo de montagem apresenta deficiência na organização, movimentação, sem fluxo contínuo, e o estado futuro que revela os ganhos adquiridos e resultados obtidos na prática com a cultura Lean implementada.

Trata-se de um complexo desafio, pois ao contrário do segmento automotivo, onde surgiu o conceito, no ramo petrolífero esta filosofia tem caráter embrionário, que está sendo desenvolvido como diferencial competitivo uma vez que este segmento está se tornando cada vez mais visado pelos concorrentes.

\section{RefERENCIAL TEÓRICO}

\subsection{O LEAN MANUFACTURING}

A Produção Enxuta surgiu no Japão, no período pós Segunda Guerra Mundial, cuja proeminente aplicação se deu na Toyota Motor Company. Devastado pela guerra, o Japão não dispunha de recursos para realizar altos investimentos necessários para a implantação da produção em massa, que caracterizava o sistema implantado por Henry Ford e General Motors. Além disso, no país existiam outras séries de problemas e desafios a serem contornados como: mercado interno limitado e demandando uma variedade de produtos; mão-de-obra organizada, existência de vários fabricantes de veículos no mundo, interessados em ingressar no Japão, dentre outros.

A partir daí, surgiu a necessidade de se criar um novo modelo gerencial, nascendo, assim, o Sistema Toyota de Produção ou Manufatura Enxuta (Lean Manufacturing), estruturado por TAIICHI OHNO, vicepresidente da Toyota. Os objetivos fundamentais deste novo sistema caracterizaram-se por qualidade e flexibilidade do processo, ampliando sua capacidade de produzir e competir no cenário internacional.

O conceito de Manufatura Enxuta se disseminou pelo mundo e várias são as definições desta filosofia, conforme apresentado abaixo:

Visa a eliminação de desperdícios e elementos desnecessários a fim de reduzir custos; a idéia básica é produzir apenas o necessário, no momento necessário e na quantidade requerida (OHNO, 2004).

A busca de uma tecnologia de produção que utilize a menor quantidade de equipamentos e mão-deobra para produzir bens sem defeitos no menor tempo possível, com o mínimo de unidades intermediárias, entendendo como desperdício todo e qualquer elemento que não contribua para o atendimento da qualidade, preço ou prazo requeridos pelo cliente. (SHINOHARA,1988).

Há de conferir o máximo número de funções e responsabilidades a todos os trabalhadores que adicionam valor ao produto na linha, e a adotar um sistema de tratamento de defeitos imediatamente acionado a cada problema identificado, capaz de alcançar a sua causa raiz (WOMACK; JONES, 2004).

A base da produção enxuta é a combinação de técnicas gerenciais com as máquinas a fim de produzir mais com menos recursos. A produção enxuta difere tanto da produção artesanal, quanto da produção em massa. $\mathrm{Na}$ produção artesanal, trabalhadores altamente qualificados, usando ferramentas manuais fabricam cada produto de acordo com as especificações do comprador, feitos um de cada vez. Já na produção em massa, profissionais especializados projetam produtos, que são fabricados por trabalhadores não qualificados ou semiqualificados, operando equipamentos caros e de finalidades específicas, produzindo produtos 
padronizados em grandes quantidades. Na produção em massa, o tempo ocioso precisa ser evitado, pois o maquinário tem um elevado custo. A gerência, então, acrescenta uma "reserva" na forma de estoque extra e de trabalhadores para garantir a disponibilidade de insumos ou para que o fluxo de produção não seja desacelerado. Devido ao alto custo do investimento em máquinas, a adaptação para a fabricação de novos produtos fica impedida e o consumidor é que se beneficia com os preços baixos em prejuízo da variedade.

A produção enxuta, entretanto, combina a vantagem da produção artesanal, evitando o alto custo, com a produção em massa, evitando a inflexibilidade. Para alcançar esses objetivos de produção, a gerência reúne equipes de trabalhadores com várias habilidades em cada nível da organização, para trabalharem ao lado de máquinas, produzindo grandes quantidades de bens com variedades de escolha. A produção é enxuta, porque usa menor esforço humano na fábrica, espaço físico reduzido e menor investimento em equipamentos se comparada com a produção em massa.

Segundo OHNO (2004), a Produção Enxuta surgiu como um sistema de manufatura cujo foco é otimizar os processos e procedimentos através da redução contínua de desperdícios, como, por exemplo, excesso de inventário entre as estações de trabalho, bem como tempo de espera elevado. Seus objetivos fundamentais são:

- Otimização e a Integração do sistema de manufatura: é preciso integrar todas as partes do sistema de manufatura, buscando sempre a otimização do sistema como um todo. Qualquer processo ou atividade que não agrega valor ao produto é desperdício e precisa ser eliminado. A integração e otimização de um sistema de manufatura é um processo contínuo de redução do número de etapas estanques, necessárias para completar um processo em particular;

- Qualidade: o sistema puxado precisa e exige um ambiente produtivo que forneça produtos com qualidade. Cada processo de produção deve passar produtos com qualidade para a etapa seguinte, ou seja, a qualidade deve ser assegurada ao longo de todo o processo. A Manufatura Enxuta exige que cada pessoa envolvida no processo produtivo seja educada e treinada para aceitar a responsabilidade pelo nível de qualidade do seu trabalho;

- Flexibilidade do processo: é a capacidade de obter materiais rapidamente e de preparar um processo de produção em curto espaço de tempo e a custo mínimo, ou seja, é ser capaz de suportar variações na demanda;

- Produção de acordo com a demanda: a empresa tem que organizar sua produção de acordo com os pedidos dos clientes, pois são eles a razão de ser de uma empresa. Não faz sentido produzir o que os clientes não querem.

- Manter o compromisso com clientes e fornecedores: manter os compromissos é o elo final, permitindo que as empresas fabricantes individuais se juntem em um processo industrial contínuo. Os fornecedores, clientes e funcionários precisam de uma posição clara da alta administração de que a empresa pretende permanecer competitiva no mercado. Planejar para manter os compromissos é um processo de determinar as etapas necessárias para atender aos planos de entrega, níveis de qualidade $\mathrm{e}$ margens de lucro;

- Redução do custo de produção: é o objetivo mais evidente e factível com a implementação 
da Manufatura Enxuta, que declara "guerra" ao desperdício e busca de forma determinada e contínua a redução dos custos do processo de manufatura como um todo.

Todos os objetivos acima foram estabelecidos visando ampliar a capacidade de produção de uma empresa para que ela possa competir neste cenário globalizado. As metas colocadas pela Produção Enxuta em relação aos vários problemas de produção são: zero defeito; tempo zero de preparação (setup); estoque zero; movimentação zero; quebra zero lote unitário (uma peça) e lead time zero.

Dessa forma, a essência do Sistema Toyota de Produção é a busca incessante da eliminação de toda e qualquer perda. $\mathrm{Na}$ Toyota se conhece esse princípio como "princípio do não-custo". Pela lógica tradicional, o preço era estabelecido pela empresa em que se somava o custo de produção ao lucro estimado (Preço = Custo + Lucro). Entretanto, com a concorrência cada vez mais acirrada e os consumidores cada vez mais exigentes, o preço passa a ser determinado pelo mercado (Preço - Custo = Lucro). Analisando a segunda fórmula, chega-se à conclusão de que a única maneira de se aumentar ou manter o lucro é reduzindo-se os custos.

Para a eliminação destes desperdícios e o alcance das metas estabelecidas a Produção Enxuta lança mão de um conjunto de técnicas e ferramentas como o 5S, Layout Celular, o Mapa do Fluxo de Valor (VSM - Value Stream Mapping), dentre outras.

\subsection{A FERRAMENTA $5 S$}

Define-se como 5S, basicamente a determinação de organizar o local de trabalho, conservando-o arrumado e limpo; manter as condições padronizadas, assim como a disciplina necessária para a realização de um bom trabalho. $\mathrm{O}$ nome $5 \mathrm{~S}$ vem das iniciais de cinco palavras japonesas - seiri, seiton, seiso, seiketsu e shitsuke - que querem dizer: seleção, ordenação, limpeza, padronização e disciplina.

O Programa 5S foi desenvolvido com o objetivo de transformar o ambiente das organizações e a atitude das pessoas, melhorando a qualidade de vida dos funcionários, diminuindo desperdícios, reduzindo custos e aumentando a produtividade. Apesar de fácil entendimento, seguir tais premissas não é uma tarefa tão simples e exige esforço coletivo. Outro fator que é importante ser citado, é que o programa, uma vez implantado, não se conclui, ou seja, não basta apenas implantá-lo. O 5S é um programa que necessita manutenção, que são feitas através de auditorias internas, e sua continuidade depende da colaboração de todos os funcionários em todos os níveis da organização.

Basicamente são essas as premissas do programa. De acordo com Lapa (1998), foram introduzidos mais quatro conceitos, além dos já citados. Porém a nomenclatura continua a mesma, e poucas empresas inseriram os outros acrescentados posteriormente. Portanto, basicamente, os conceitos fundamentais do programa 5S são:

- SEIRI - Significa seleção. No programa significa diferenciar o útil do desnecessário. Desta forma, busca-se eliminar tudo que não possui utilidade de modo a evitar que se transformem em problemas. Deve-se ser aplicado em todos os aspectos do ambiente de trabalho, desde as mesas até os arquivos dos computadores. Utiliza-se a estratificação para tal gerenciamento, ou seja, criam-se estratos de importância para os objetos existentes.

- SEITON - Significa arrumação/ordenação. Este senso enfoca a importância da disposição dos objetos de forma correta, ou seja, devem-se definir um lugar para as ferramentas de trabalho, guardá-las e 
obedecer às regras, onde cada objeto tem que ter nome. Portanto, o senso de arrumação tem como objetivo permitir a localização dos objetos com maior facilidade, evitando perda de tempo com a procura. Como ponto de partida para a aplicação deste senso, deve-se averiguar com frequência da utilização dos objetos, definindo o que deve ser descartado e o que deve ser mantido como itens reservas, o que deve ser guardado em locais distantes, o que deve ficar no local de trabalho e, finalmente, o que deve ser colocado sempre à disposição. Para Hirano e Yoshinaga (1996), organizar é padronizar a armazenagem.

- SEISO - Significa limpeza. Este senso busca acabar com a sujeira e o lixo, na forma de inspeções. Com isso, busca-se um local de trabalho limpo e agradável. Segundo Hirano e Yoshinaga (1996), se o local de trabalho está sujo, você pode facilmente se sentir deprimido. Limpe e transforme seu local de trabalho em um lugar confortável e mantenhao assim.

Para produzir com qualidade é fundamental que se trabalhe com alta precisão. Para isso devem-se ter as máquinas e ferramentas sempre limpas. Além disso, a questão da aparência externa da fábrica, tanto para seus consumidores, quanto para a sociedade, também são salientadas neste senso. Portanto, o programa encara a questão da limpeza, tanto no seu real significado, como na questão da inspeção através dela.

Hirano e Yoshinaga (1996) já disseram: Um local de trabalho aprazível começa com o piso limpo.

- SEIKETSU - Significa saúde e higiene. Basicamente, o objetivo deste senso é manter os três sensos anteriores, organização, arrumação e limpeza. Este item inclui outras considerações, tais como cores, formas, iluminação, ventilação, vestuário, higiene pessoal e tudo o que causar a impressão de limpeza. Destaca-se disso tudo, o gerenciamento das cores, desde as paredes do ambiente até a cor dos uniformes dos funcionários. Além disso, o gerenciamento visual, que consiste na análise crítica do que é perceptível ao olho humano e a criatividade para a implantação de técnicas que tornem o ambiente de trabalho mais agradável, são cruciais para a introdução deste senso.

- SHITSUKE - Significa autodisciplina. Consiste na execução das tarefas da maneira como elas realmente deveriam ser feitas. A ênfase deste senso está na criação de um ambiente de trabalho agradável, em que todos os usuários deste ambiente tenham bons hábitos. É necessário salientar que disciplina não equivale a algo negativo ou submissão às regras existentes, e sim às atitudes que irão ajudar as pessoas a terem bons hábitos e a respeitar os outros em seu cotidiano. Basicamente, estes conceitos de disciplina parecem ser fáceis de serem alcançados, mas as experiências de implantação do programa identificam este senso como sendo um dos de maiores dificuldades, pois envolve comportamentos pessoais, ou seja, mudança de hábitos que devem ser alterados gradativamente.

Nas fábricas mais bem sucedidas, sempre há pessoas que sabem muito bem manter a disciplina, afirmam Hirano e Yoshinaga (1996).

\subsection{Mapeamento do Fluxo de Valor (MFV)}

Realizar o Mapeamento do Fluxo de Valor é de extrema importância na Produção Enxuta, pois 
permite a visão de todo o fluxo de valor dos processos produtivos.

De acordo com Rentes, Nazareno e Silva (2003), o Mapeamento do Fluxo de Valor (MFV) é um método simples de modelagem de empresas com um procedimento para a construção de cenários de manufatura, que leva em consideração tanto o fluxo de materiais como o fluxo de informações. Por este motivo é considerada uma ferramenta imprescindível para o processo de visualização da situação atual da organização e construção da situação futura.

As vantagens da utilização do Mapeamento do Fluxo de Valor (MFV), segundo Rother e Shook (2003) são:

- Permite a visualização de todo o fluxo e não somente dos processos individuais;

- Ajuda na identificação das fontes dos desperdícios;

- Fornece uma linguagem comum para tratar dos processos de manufatura;

- Torna as decisões sobre o fluxo visíveis, facilitando sua discussão;

- Integra conceitos e técnicas enxutas;

- Identifica a relação entre o fluxo de material e o fluxo de informação.

A principal utilidade do Mapeamento do Fluxo de Valor (MFV) é a identificação de quando e onde o valor começa a ser acionado e onde existem desperdícios, pois ao mapear o fluxo de valor os integrantes do time se tornam mais objetivos na eliminação das perdas.

Rentes, Queiroz e Araújo (2004) afirmam que o mapeamento pode servir como um catalisador na análise do processo, possibilitando o compartilhamento do conhecimento sobre o processo com todos os seus componentes, além de permitir a identificação de pontos que necessitem ser melhorados, auxiliando o trabalho em equipe na obtenção de resultados.

\subsection{PADRONIZAÇÃO}

Um processo padronizado é um método efetivo e organizado de produzir sem perdas. A padronização almeja o desempenho máximo dos colaboradores em suas atividades ou operações através da repetição dos movimentos e das operações. A falta de padronização esconde falhas e leva ao desperdício. Todo o processo realizado em determinada etapa da fabricação é registrado e documentado em instruções de trabalho. Estas instruções preveem as operações a serem realizadas, a sequência de cada uma delas, o tempo necessário para execução, as ferramentas requeridas, o espaço, os equipamentos e dispositivos necessários e também os parâmetros do processo (regulagem de equipamentos, máquinas, etc). $\mathrm{O}$ registro das operações é de grande valia para poder detectar as operações ou movimentos que não agregam valor ao produto, os movimentos que são desperdícios, a necessidade de equipamentos ou dispositivos. Em algumas empresas japonesas, as operações são filmadas e comparadas à documentação, buscando melhoria contínua das operações e. posteriormente, são propostas ações de melhoria no processo para eliminação de movimentos desnecessários, estudo de novos dispositivos e rearranjo físico, a fim de diminuir a distância de transporte. O desenvolvimento de um plano de padronização de processo inicia-se, geralmente, a partir de um desenho de produto. A partir das informações do projeto, passa-se a sequenciar as operações do plano macro. Em uma fase posterior, estas operações são detalhadas, sendo que o nível de detalhe depende de características da empresa, para avaliar se o plano está satisfazendo às expectativas no sentido de alcançar a eficiência e eficácia desejadas.

A padronização no processo de produção busca intensamente reduzir o tempo padrão de realização de determinada tarefa através da eliminação de ações e movimentos desnecessários, realizados por 
operadores. O treinamento do trabalho é utilizado também para treinar novos funcionários, garantindo um aprendizado rápido e eficaz, pois continua utilizando o roteiro da operação padrão até que estejam familiarizados com as técnicas.

Segundo Ohno (2004), os elementos a se considerar no trabalho padrão são: operário, máquina e materiais, se não houver a combinação efetiva, os operários se sentirão alienados e incapacitados de produzir com eficácia. Os padrões não devem ser estabelecidos de cima para baixo, e sim pelos próprios operadores da produção. Somente quando o sistema da planta é considerado como um todo, os padrões para cada departamento de produção tornam-se flexíveis e livres de defeitos.

Percebe-se que o trabalho padronizado é essencial para a sustentação da produtividade, da qualidade e principalmente da estabilidade da produção.

\subsection{Layout Celular}

Segundo Rentes, Queiroz e Araújo (2004), os motivos que tornam importantes as decisões sobre arranjo físico são porque eles afetam a capacidade de instalação e a produtividade das operações. Portanto uma mudança adequada no tipo de arranjo físico pode aumentar a produção com a utilização dos mesmos recursos. As mudanças implicam no dispêndio de consideráveis somas de dinheiro.

De acordo com Slack, Chambers e Johnston (2002), o layout da fábrica deve permitir que os postos de trabalho fiquem próximos uns dos outros para evitar a geração de estoques entre eles, além de garantir que os estágios de produção fiquem visíveis para tornar o fluxo transparente a todas as partes do processo, facilitando a movimentação dos funcionários e materiais.

Rother (2003) afirma que a melhor maneira de projetar o espaço físico de uma célula é organizar as máquinas, equipamentos e material necessários como se somente um operador fabricasse o produto do início ao fim. Essa prática permite projetar um processo que evita as ilhas isoladas de atividades, minimiza o acúmulo de estoques intermediários, elimina caminhadas excessivas, remove obstáculos e aproxima as etapas de criação de valor, uma às outras.

Silva e Rentes (2002) citam algumas vantagens do layout celular:

- Facilita o retrabalho (itens defeituosos);

- A ausência de corredores implica na eliminação de veículos e pessoas;

- Facilita a movimentação de materiais e ferramentas;

- Fluxo contínuo no setor de montagem;

- Elimina os problemas com o reposicionamento de algumas máquinas;

- Diminui os custos unitários para altos volumes.

O mesmo autor ainda acrescenta: "as células de manufatura, em comparação aos layouts tradicionais, provocam o aumento de 10 a $20 \%$ na produtividade da mão-de-obra direta".

\section{MATERIAIS e MÉtodos}

A pesquisa realizada trata de um estudo de caso com uma abordagem de pesquisa qualitativa, pois mostra melhorias da qualidade do processo produtivo, porém também mostra uma abordagem de pesquisa quantitativa com ênfase em análises numéricas dos resultados, com uso de estatísticas básicas 


\subsection{EMPRESA ESTUDADA}

Uma empresa brasileira (doravante denominada empresa A) foi objeto do estudo, sendo uma organização especializada na fabricação, montagem e testes de equipamentos utilizados na extração de petróleo.

Trata-se de uma empresa multinacional de grande porte, com aproximadamente 800 funcionários, na Planta estudada, localizada no município de Taubaté, na região do Vale do Paraíba, no interior do estado de São Paulo, atua no mercado petrolífero e é uma das lideres de mercado no seu segmento.

Tem como princípio acompanhar a expansão de seu principal cliente, que é o maior produtor de petróleo do Brasil e um dos maiores do mundo, com perspectivas concretas de crescimento devido à exploração do Pré Sal.

\subsection{AplicaÇão Prática}

O roteiro adotado neste trabalho para a implementação da Gestão Lean foi estabelecido baseando-se nos conceitos pesquisados sobre o tema.

A primeira etapa da implantação da Gestão Lean foi alinhar o conceito das suas ferramentas com uma equipe de líderes que foi a disseminadora do conceito para toda fábrica. Essa equipe era composta por pessoas com perfil de multiplicador. Uma vez o conceito difundido na empresa, a implantação se deu com maior facilidade, tendo em vista que os resultados foram aparecendo viabilizando a credibilidade e eficácia das Ferramentas utilizadas. O envolvimento de todos foi crucial para a evolução do projeto.

A segunda etapa aconteceu em paralelo com a primeira, onde foi feito um Mapeamento do Fluxo de
Valor (MFV) e desenhado o objetivo a ser atingido com a implantação da Gestão Lean.

No Mapeamento do Fluxo de Valor (MFV) foi retratado o estado atual que a empresa se encontrava, mostrado na FIG.1, onde está evidenciando a desorganização, justificando a implantação urgente da Gestão Lean.

Após ter sido retratado o estado atual em que a empresa estava operando no seu dia-a-dia, traçou-se um objetivo a ser alcançado, utilizando inúmeras ferramentas, porém com a base estruturada na Ferramenta $5 \mathrm{~S}$.

O estado futuro desenhado como objetivo teve como fundamento básico tornar o processo com fluxo de materiais mais estratégico ao longo da cadeia produtiva, diminuindo o Lead Time de montagem, como ilustra a FIG. 2.

Após a meta ter sido traçada e apresentada para toda a equipe de liderança começou-se, então, a colocar em prática as ações. A empresa A do Brasil Ltda, não tinha área de montagem definida, o equipamento era montado em qualquer lugar da montagem com espaço disponível. Os módulos do equipamento também eram montados de forma aleatória, para depois serem levados para um único lugar onde acontecia o Stackup. Com essa montagem desorganizada, perdia-se muito tempo com a movimentação do equipamento, perdiam-se muitas peças e não tinha um fluxo de trabalho.

Decidiu-se então organizar a montagem, fazendo uma divisão da linha em Células de montagem de forma que os equipamentos fossem montados numa sequencia lógica e num fluxo contínuo. Criou-se uma nova área de montagem que foi dividida em células, classificadas por família de conjuntos divididos por módulos, que por sua vez quando acoplados formam o equipamento completo que é lançado ao fundo do mar. 


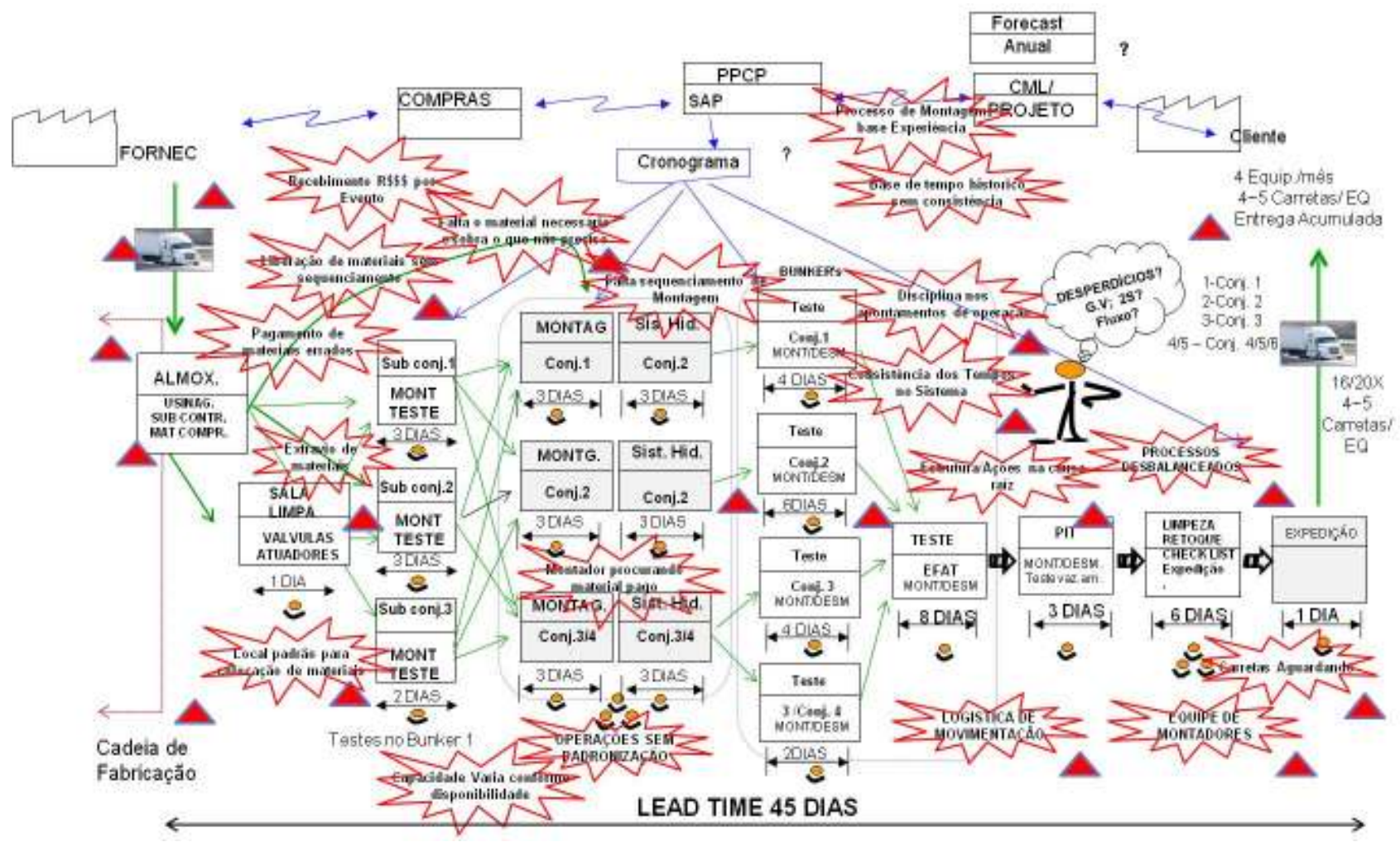

Figura 1 - Mapa do fluxo de valor atual.

Fonte - Extraído do Relatório apresentado à empresa, 2011.

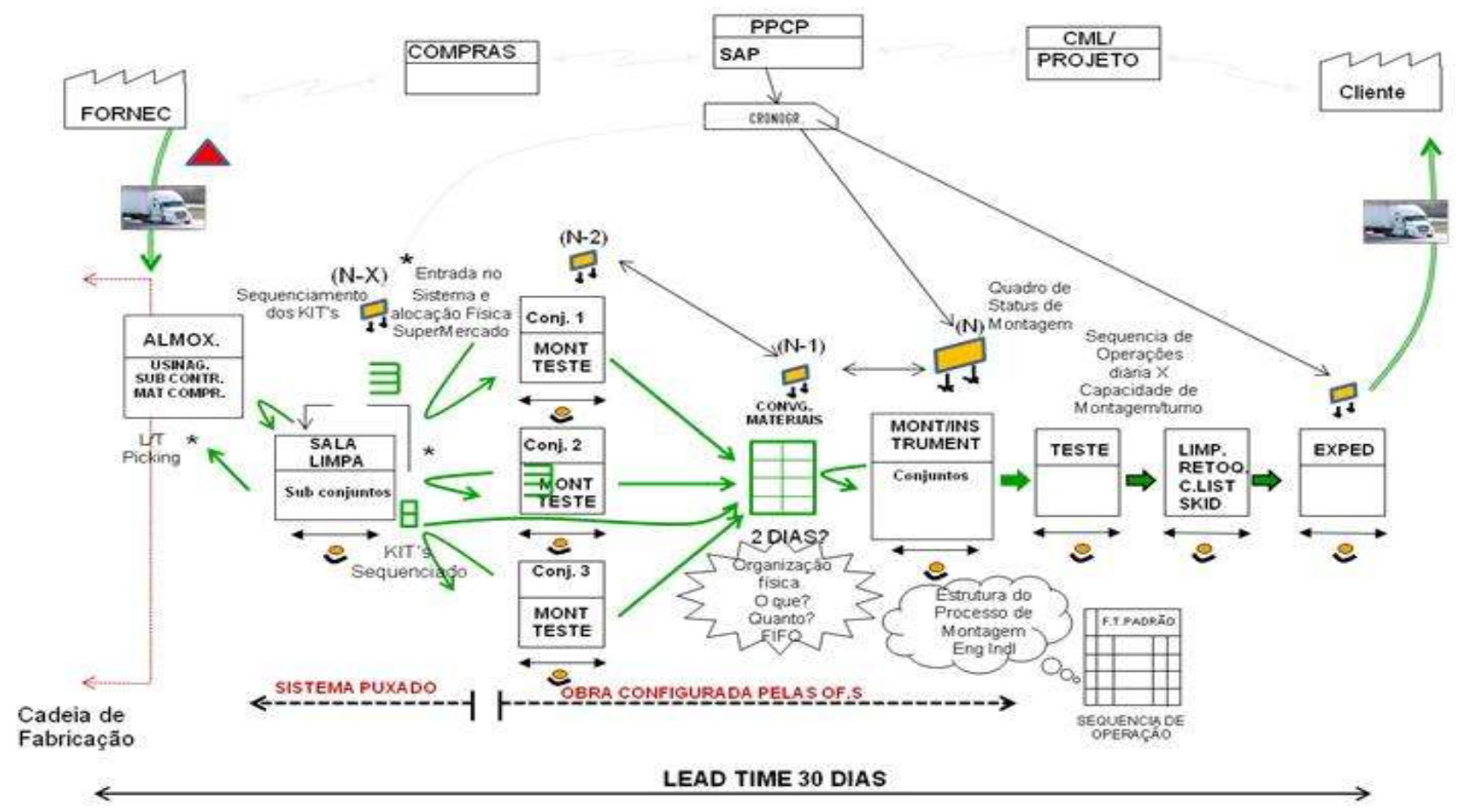

Figura 2 - Mapa do fluxo de valor futuro.

Fonte - Extraído do Relatório apresentado à empresa, 2011. 
O equipamento é formado pela Base Adaptadora (BAP), seguindo pela Árvore de Natal Molhada (ANM), e finalizada com a Capa da Árvore (Tree Cap). Sendo assim a área de conjuntos completos também foi divida em 3 células seguindo o fluxo de movimentação do material, conforme a FIG. 3, que mostra a nova disposição.

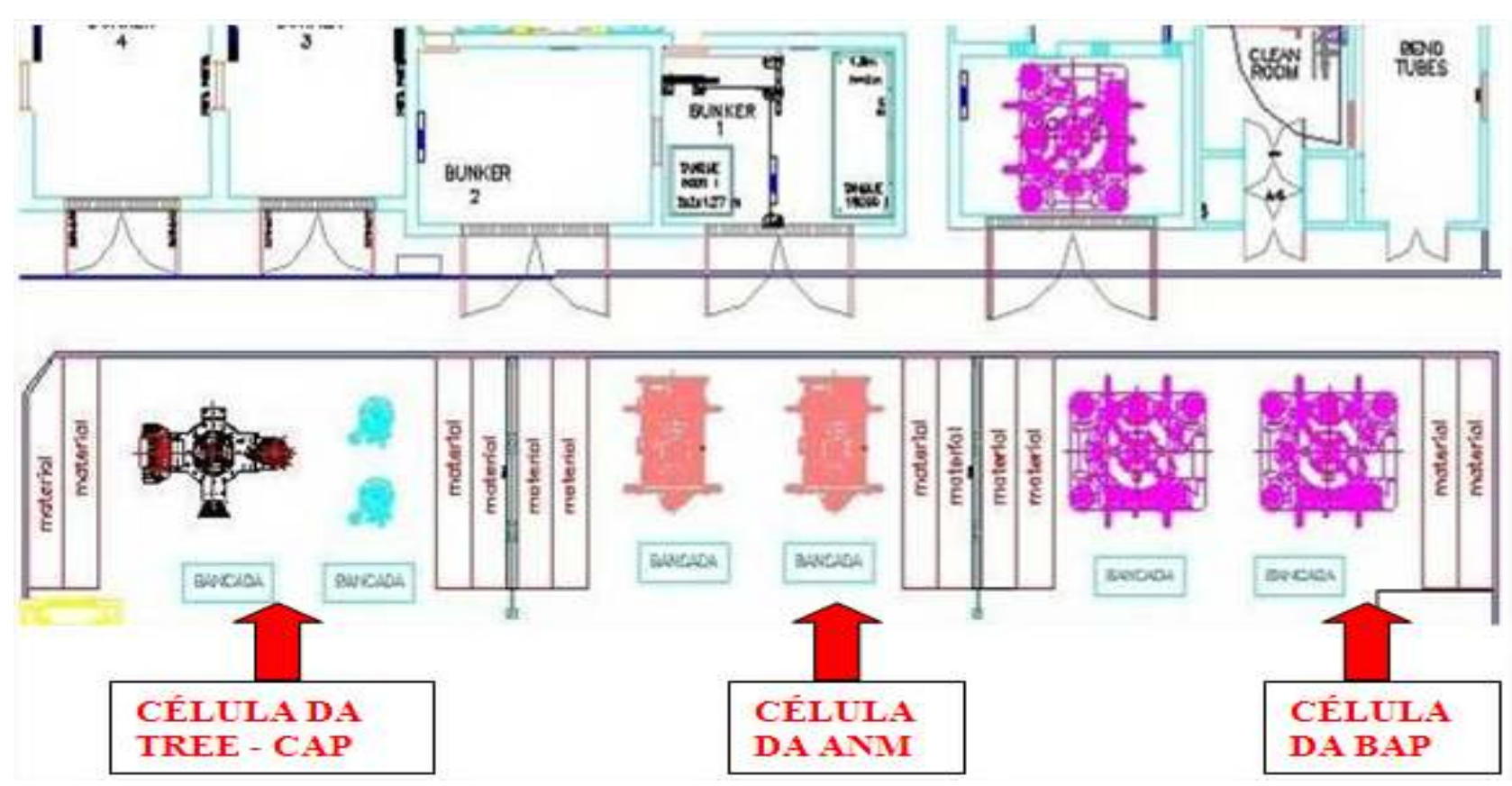

Figura 3 - Layout divido por Células de montagem.

Fonte - Extraído do Relatório apresentado à empresa, 2011.

Nota-se pelo novo layout que as áreas foram dividas com espaço suficiente para a montagem dos seus módulos. Todas as células têm bancadas para auxiliar a montagem dos equipamentos, além de áreas definidas para abastecimento de material. Esse layout também foi definido juntamente com a liderança da fábrica visando à fluidez do processo. Como se pode ver também na FIG. 3, as células de montagem estão posicionadas em frente aos Bunker de teste, onde posteriormente à montagem, são executados testes de simulação com o equipamento.

Estabelecida a nova disposição, focou-se na implementação do 5S, agora célula a célula, envolvendo cada vez mais os operadores.
Foi feito um cronograma, dividindo e definindo uma semana para cada célula até finalizar a implementação da ferramenta 5S. Nomeou-se um operador da célula em cada turno, para ser o líder e responsável, em seu núcleo, pela sustentabilidade do programa.

Toda a arrumação, limpeza e organização, descarte do desnecessário, higienização era feita pelos próprios operadores. Pode-se ver na FIG. 4, como estavam às células antes da Implementação do $5 \mathrm{~S}$ e como ficaram após as semanas de implementação do processo. 

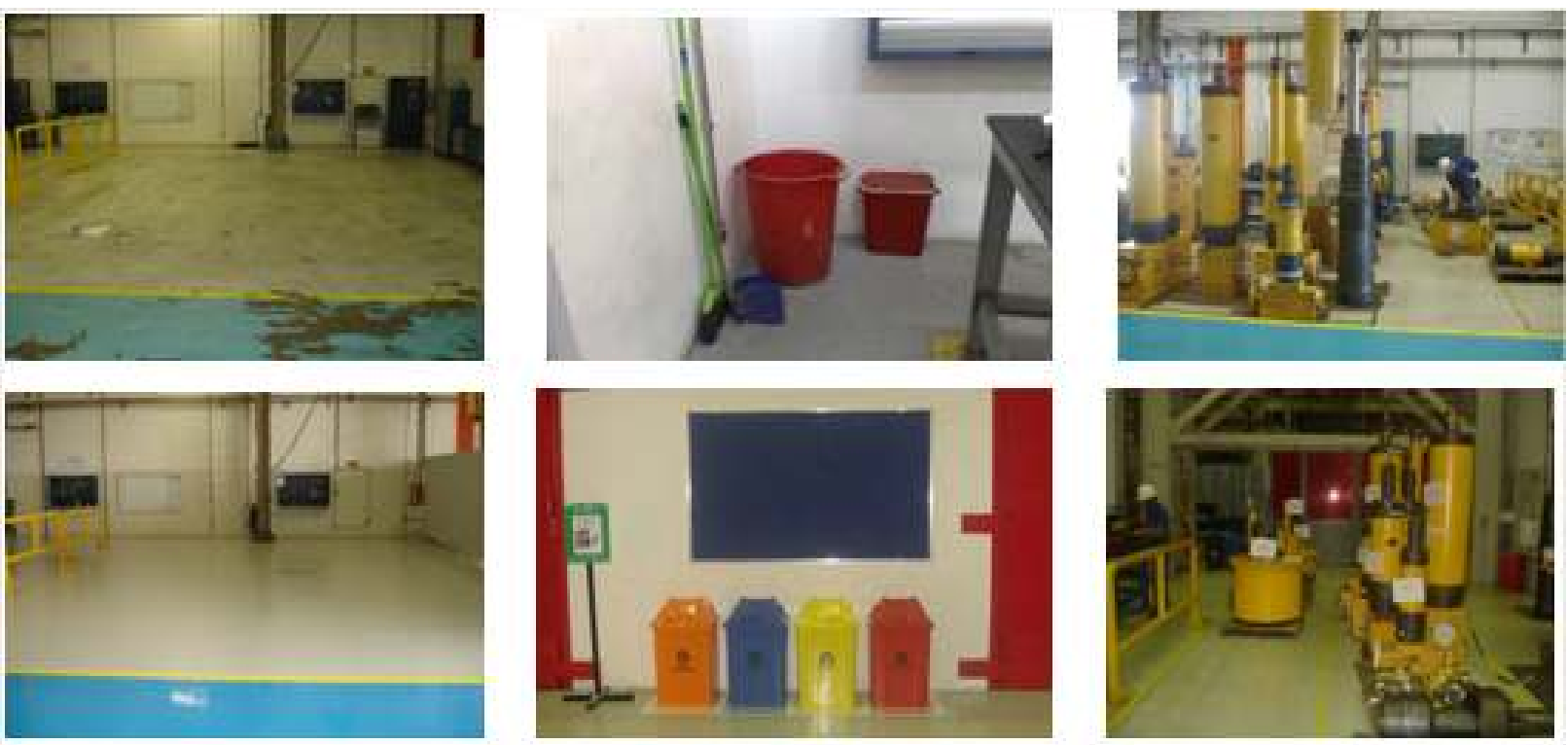

Figura 4 - Antes e Depois do 5S.

Fonte - Extraído do Relatório apresentado à empresa, 2011.

Com as grandes mudanças observadas nas figuras acima, consegue-se constatar que a implantação que os "S" de Seiri (organização), Seiton (arrumação) e Seiso (limpeza), obtiveram sucesso. Porém, ainda restavam $2 S$ a ser implantados, Seiketsu (padronização) e Shitsuke (disciplina).

Para o "S" Shitsuke (disciplina), os líderes de cada célula foram responsáveis por gerenciar a organização, limpeza e arrumação de sua célula. Ainda ao final de cada mês o conceito dos $5 \mathrm{~S}$ era reciclado com os operadores, que passaram a ser auto gerenciáveis.

Ficando por fim o "S" Seiketsu (padronização), que teve um trabalho desenvolvido pela Engenharia Industrial de procedimentalizar todos os processos de montagem em manuais de instrução que estavam disponíveis em cada célula de montagem.
Com esses procedimentos de montagem, todo operador desde o iniciante até o mais experiente, segue o mesmo curso de montagem. Com isso os conhecimentos dos funcionários mais experientes, foram passados para o papel. Na FIG. 5, pode-se verificar um exemplo de uma folha de procedimento de montagem.

Esses procedimentos, além de disponíveis nas células de montagem, são cadastrados por uma numeração no sistema, que por sua vez fica mencionado na lista de materiais e na ordem de execução da atividade. $\mathrm{O}$ fácil acesso aos procedimentos facilitou a padronização da montagem do equipamento como um todo. 


\begin{tabular}{|c|c|c|}
\hline Q QUE FAZER ? & COMO EXECUTAR ? & 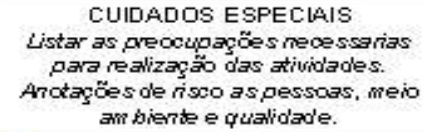 \\
\hline $\begin{array}{l}\text { 04) Pieparaça do } \\
\text { bonmet. }\end{array}$ & 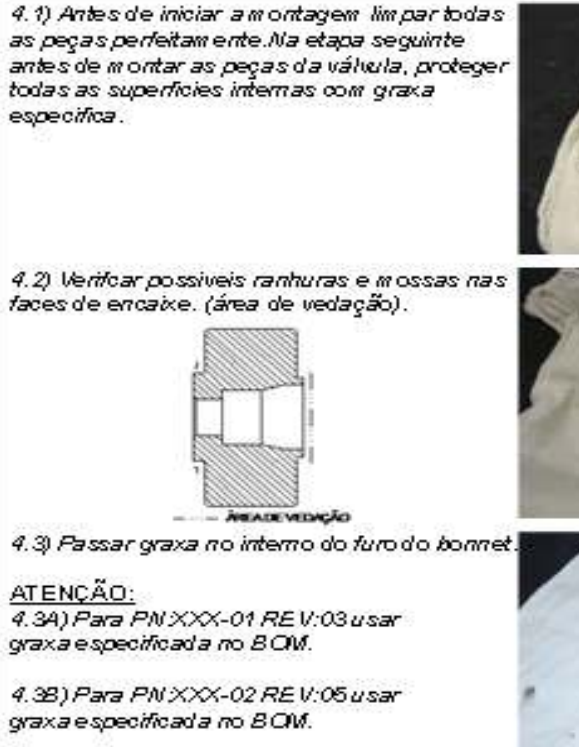 & 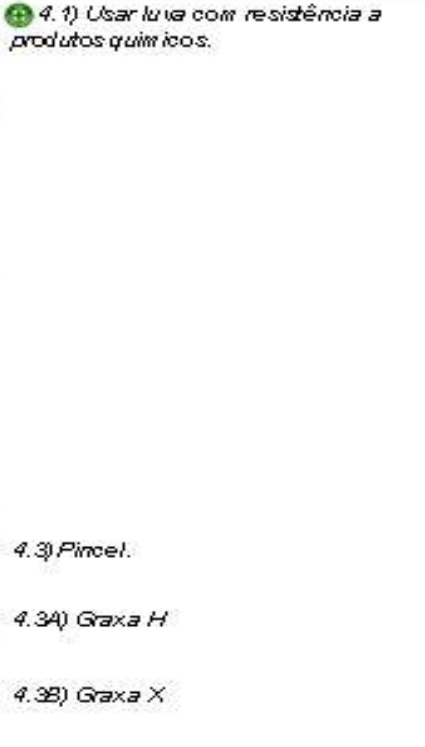 \\
\hline
\end{tabular}

Figura 5 - Padronização das Atividades com procedimentos de montagrem. Fonte - Extraído do Relatório apresentado à empresa, 2011.

\section{ANÁLISE dos RESULTADOS}

Os resultados iniciais apresentam índices extremamente satisfatórios em relação à redução do ciclo de montagem, redução de não conformidades na montagem e eliminação de desperdícios no processo produtivo. Observou-se que as etapas estabelecidas foram seguidas, mostrando a eficácia da implementação da Gestão Lean por meio dos resultados obtidos. Conseguiu-se então implantar com sucesso a Gestão Lean, sustentada por suas ferramentas, na linha de montagem final, agora os passos são controlar a sustentabilidade do programa e melhorar continuamente os processos de montagem. O próximo desafio é estender o programa da implementação da Gestão Lean para todos os setores da Empresa A do Brasil Ltda, tendo como exemplo de sucesso e experiência positiva, a linha de montagem final.

$\mathrm{Na}$ Tabela 1 a seguir, podem-se ver os dados referentes às não confomidades, que foram coletados durante o ano todo, e utilizando um software de análises estatísticas, verificou-se a melhoria do processo após a nova sistemática de trabalho. 
Tabela 1

Redução de Não Conformidades

\begin{tabular}{|c|c|c||}
\hline Mês & Meta & Não Conformidade Montagem \\
\hline Janeiro/ll & 45 & 221 \\
\hline Fevereiro/ll & 43 & $\mathbf{8 7}$ \\
\hline Março/ll & 40 & $\mathbf{7 5}$ \\
\hline Abril/ll & 37 & 63 \\
\hline Maio/ll & 35 & $\mathbf{5 7}$ \\
\hline Junho/ll & 32 & 44 \\
\hline Julho/ll & 30 & 30 \\
\hline Agosto/ll & 27 & $\mathbf{2 3}$ \\
\hline Setembro/ll & 25 & $\mathbf{1 6}$ \\
\hline Outubro/ll & 22 & $\mathbf{l l}$ \\
\hline Novembro/ll & 20 & 9 \\
\hline Dezembro/ll & 17 & 6 \\
\hline
\end{tabular}

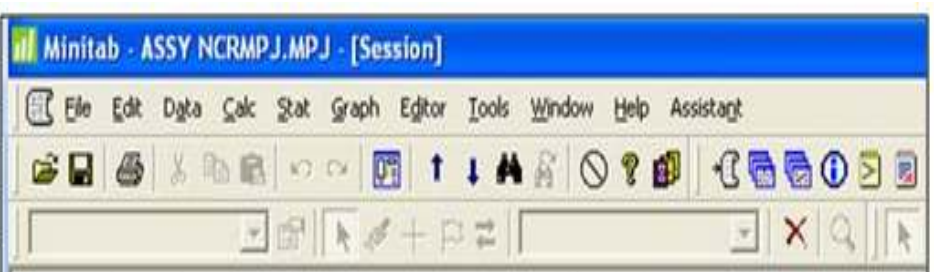

Descriptive Statistics: Năo Conformidade ANTES, Năo Conformidade DEPOIS

Variable $N N^{2}$ Mean $S E$ Hean Sedev Minisus 01 Median

$\begin{array}{lllllllll}\text { Năo Contornidade ANTEs } & 5 & 0 & 100.6 & 30.5 & 68.3 & 57.0 & 60.0 & 75.0\end{array}$

$\begin{array}{lllllllll}\text { Näo Conformidade DEPOIS ? } & 0 & 19.86 & 5.12 & 13.53 & 6.00 & 9.00 & 16.00\end{array}$

Variable 03 Maxiaua

Wăo Conformidade AMTES $154.0 \quad 221.0$

Năo Confornidade DEPOIS $30.00 \quad 44.00$

Fonte - Extraído do Relatório apresentado à empresa, 2011.

Verificou-se que o processo passa a ser mais estável na Tab.1, pois diminui-se o número de não conformidades, bem como o desvio padrão do processo de 68,3 passou a ser 13,53, caracterizando uma melhora significativa, que também pode ser melhor refletida na carta de controle do processo, ilustrada pela FIG. 6.

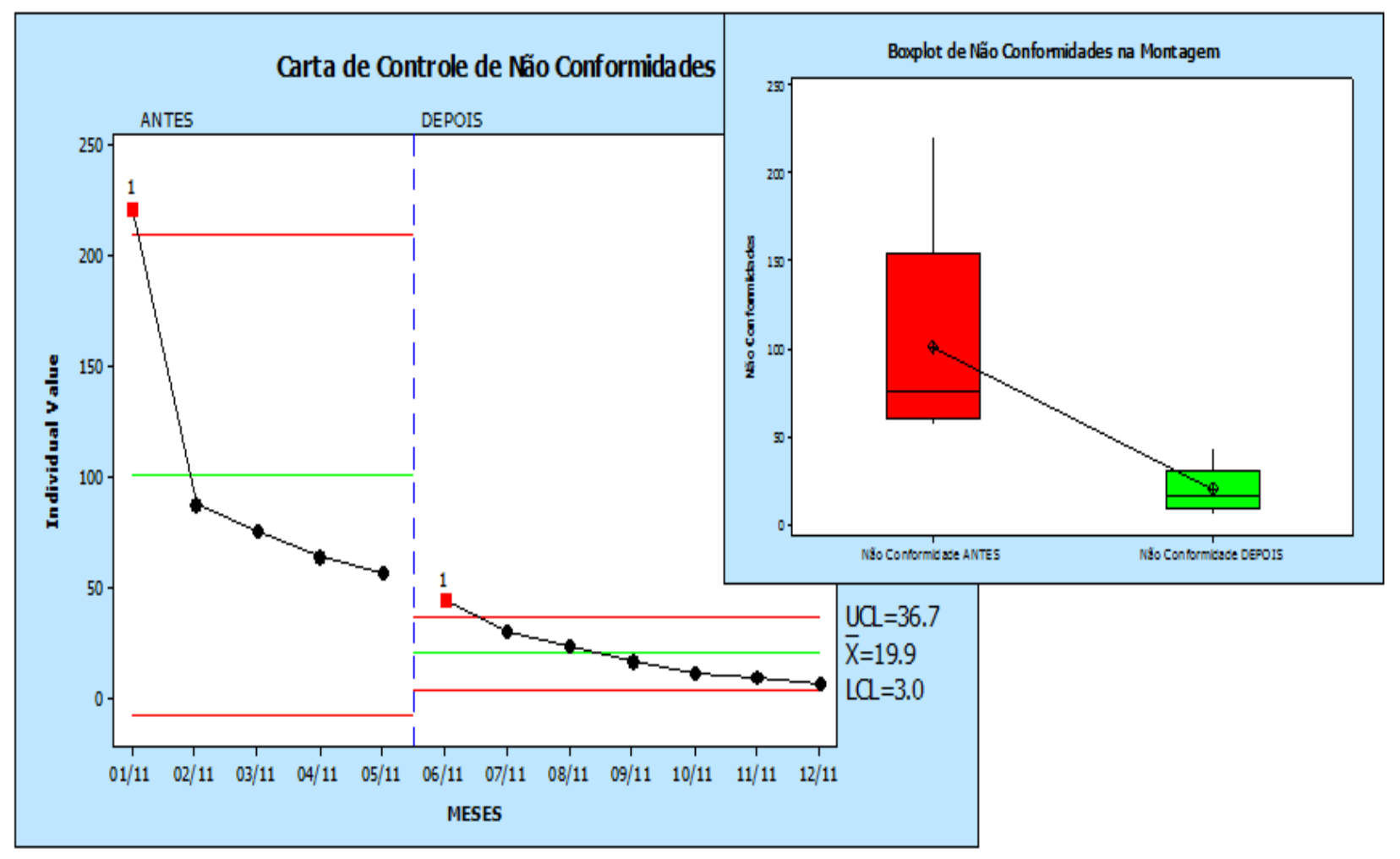

Figura 6 - Carta de controle evidenciando a Redução de Não Conformidades / Mudança de processo.

Fonte - Extraído do Relatório apresentado à empresa, 2011 
Na FIG.6 verifica-se a redução de não conformidades, que passa a ser acentuada a partir do mês de maio de 2011, período em que passa a ser absorvida a nova cultura e a adoção, na íntegra, das ferramentas Lean por toda equipe fabril.

Além da melhoria na qualidade do processo, foram coletados dados referente ao tempo de execução de cada uma de suas atividades. A Tabela 2 evidencia a redução dos tempos de processo. Cada redução de tempo alcançada nas diversas atividades, fez com que o resultado obtido no final de toda a linha de montagem tivesse uma redução de $33 \%$, pois de 45 dias para a montagem do equipamento, o processo de montagerm completo passou a ser concluído em 30 dias.

Tabela 2

Resultados Obtidos nas Células de Montagem - Redução de Lead Time.

\section{Conectores}

\begin{tabular}{|l|c|c|c|}
\hline \multicolumn{1}{|c|}{ TABElA } & $\begin{array}{c}\text { Estado } \\
\text { Atual }\end{array}$ & $\begin{array}{c}\text { Estado } \\
\text { Futuro }\end{array}$ & $\begin{array}{c}\text { Ganho } \\
(\%)\end{array}$ \\
\hline Etapas do Processo & 6 & 4 & 33 \\
\hline Tempo de Espera (h) & 69 & 35,5 & 48 \\
\hline Tempo do Ciclo (h) & 5 & 4 & 20 \\
\hline Lead Time Total (h) & 74 & 39,5 & 46 \\
\hline ValorAgregado & $7,2 \%$ & $11,26 \%$ & $4,06 \%$ \\
\hline
\end{tabular}

\section{Subcomponentes - Sala Limpa}

\begin{tabular}{|l|c|c|c|}
\hline TABELA & $\begin{array}{c}\text { Estado } \\
\text { Atual }\end{array}$ & $\begin{array}{c}\text { Estado } \\
\text { Futuro }\end{array}$ & $\begin{array}{c}\text { Ganho } \\
(\mathbf{8})\end{array}$ \\
\hline Etapas do Processo & 5 & 4 & 20 \\
\hline Tempo de Espera (h) & 79 & 76 & 3 \\
\hline Tempo do Ciclo (h) & 15 & 12 & 3 \\
\hline Lead Time Total (h) & 94 & 88 & 6 \\
\hline Valor Agregado & $15,95 \%$ & $13,63 \%$ & 0 \\
\hline
\end{tabular}

\section{Blocos}

\begin{tabular}{|l|c|c|c|}
\hline \multicolumn{1}{|c|}{ TABELA } & $\begin{array}{c}\text { Estado } \\
\text { Atual }\end{array}$ & $\begin{array}{r}\text { Estado } \\
\text { Futuro }\end{array}$ & $\begin{array}{c}\text { Ganho } \\
(83)\end{array}$ \\
\hline Etapas do Processo & 5 & 4 & 20 \\
\hline Tempo de Espera (h) & 80 & 64 & 20 \\
\hline Tempo do Ciclo (h) & 5 & 4 & 20 \\
\hline Lead Time Total (h) & 85 & 68 & 20 \\
\hline Valor Agregado & $5,88 \%$ & $5,88 \%$ & 0 \\
\hline
\end{tabular}

\section{Subcomponentes}

\begin{tabular}{|l|c|c|c|}
\hline \multicolumn{1}{|c|}{ TABElA } & $\begin{array}{c}\text { Estado } \\
\text { Atual }\end{array}$ & $\begin{array}{c}\text { Estado } \\
\text { Futuro }\end{array}$ & $\begin{array}{c}\text { Ganho } \\
(\text { (3) }\end{array}$ \\
\hline Etapas do Processo & 5 & 4 & 14 \\
\hline Tempo de Espera (h) & 79 & 74,5 & 4,5 \\
\hline Tempo do Ciclo (h) & 2 & 1 & 1 \\
\hline Lead Time Total (h) & 81 & 78,5 & 2,5 \\
\hline ValorAgregado & 2,46 & 1,27 & 0 \\
\hline
\end{tabular}

Fonte - Extraído do Relatório apresentado à empresa, 2011.

$\mathrm{Na}$ Tabela 2 podem-se ver exemplos de ganhos nas atividades e sub atividades realizadas nas células de montagem, Trabalhar com a nova cultura, atingindo os resultados apresentados acima, motivou a todos a traçar metas desafiadoras buscando melhorar na performance de trabalho. Por fim a Tabela, apresenta um resumo detalhado, com os principais ganhos obtidos após a implementação do conceito de Gestão Lean, por meio de um comparativo do "antes" e "depois" da ferramenta implementada. 
Tabela 3

Resumo dos Resultados

\begin{tabular}{|c|c|}
\hline \multicolumn{2}{|c|}{ PRINCIPAIS GANHOS OBTIDOS COM A IMPLEMENTAÇÃO DA GESTÃO LEAN } \\
\hline $\begin{array}{l}\text { ANTES DA IMPLEMENTAÇÃO DO 5S: } \\
\text { - Tempo de processo de montagem final do equipamento: } 45 \\
\text { dias }\end{array}$ & $\begin{array}{l}\text { DEPOIS DA IMPLEMENTAÇÃO DO 5S: } \\
\text { - Tempo de processo de montagem final do equipamento: } 30 \text { dias - } \\
\text { redução de } 33,33 \% \text { no tempo de processo; }\end{array}$ \\
\hline - Processo de montagem sem padronização; & - Engenharia Industrial padronizou o processo de montagem; \\
\hline $\begin{array}{l}\text { - Processo de montagem sem local definido para os } \\
\text { equipamentos; }\end{array}$ & - Elaborado um novo Layout, dividido por células de montagem; \\
\hline - Sem Projetos de redução de custo no processo de montagem; & $\begin{array}{l}\text { - Inúmeros projetos de redução de custo, totalizando uma } \\
\text { economia de aproximadamente } \mathrm{R} \$ 300.000,00 \text {, relatados em } \\
\text { formato A3; }\end{array}$ \\
\hline $\begin{array}{l}\text { Processo de Montagem completamente desorganizado e sem } \\
\text { fluxo contínuo de materiais; }\end{array}$ & $\begin{array}{l}\text { - Processo de Montagem organizado com fluxo contínuo de } \\
\text { materiais; }\end{array}$ \\
\hline - Não existia o conhecimento da Ferramenta 5S; & \\
\hline - Sem estrutura para implementar uma Gestão de processos & $5 \mathrm{~S}$ \\
\hline - Alto índice de não conformidade no processo de montagem; & $\begin{array}{l}\text { - Desenvolvido o 5S para transformar todos os processos em Lean; } \\
\text { - Redução do índice de não conformidade; }\end{array}$ \\
\hline
\end{tabular}

Fonte - Extraído do Relatório apresentado à empresa, 2011.

\section{ConClusões}

O estudo realizado permitiu demonstrar os passos da implementação da Gestão Lean, utilizando ferramentas poderosas como o $5 \mathrm{~S}$, Padronização, Layout Celular, Mapeamento de Fluxo de Valor, no processo de montagem final de uma empresa do ramo petrolífero.

Por meio das ferramentas Lean foi possível a mudança de layout, reduzir os tempos de processos, reduzir o inventário de materiais, eliminar os desperdícios, reduzir as não conformidades, aumentar espaço de armazenamento, melhorar as condições de trabalho dos colaboradores, entre outras melhorias.

O bem estar no ambiente de trabalho, que essa nova filosofia implementada no setor de montagem final do equipamento trouxe para os funcionários, vem mantendo a sustentabilidade do programa.

A ideia é fazer com que os ganhos e melhorias obtidos com a implementação das ferramentas no setor da montagem, sirvam de exemplo para facilitar a quebra dos paradigmas no período de implementação da Gestão Lean nos demais setores, até que a implementação seja concluída em toda empresa.

Como o atendimento desses princípios Lean, na maioria das situações, viabiliza a ampliação do nível de competitividade da empresa, através de processos ágeis e flexíveis e com utilização otimizada de recursos, pode-se dizer que a união das ferramentas Lean, utilizadas nessa implantação, foi de suma importância para a obtenção dos resultados apresentados, passando a ganhar credibilidade dos colaboradores,

O conceito da Gestão Lean, na empresa estudada, passa a ser visto como uma possibilidade real de constantemente rever e reformatar o ambiente de trabalho, dando suporte à melhoria contínua, necessária ao sucesso da empresa.

e-xacta, Belo Horizonte, v. 5, n. 2, p. 111-126. (2012). Editora UniBH Disponivel em: www.unibh.br/revistas/exacta/ 


\section{REFERÊNCIAS}

HIRANO, H.; YOSHINAGA, C. 5 S na Prática. $1^{\text {a }}$.ed. São Paulo: IMAM, 1996.

LAPA, R.P ; Praticando os 5 sensos. $1^{\text {a }}$.ed. Rio de Janeiro: Qualitymark, 1998.

OHNO, T. O Sistema Toyota de Produção: além da produção em larga escala. Reimpressão 2004. Porto Alegre: Artes Médicas,2004.

RENTES, A.F., QUEIROZ, J.A., ARAUJO, C.A.C. Transformação Enxuta: Aplicação do Mapeamento do Fluxo de Valor em uma Situação Real. In: XXIV ENCONTRO NACIONAL DE ENGENHARIA DE PRODUÇÃO. Florianópolis-SC, 2004.

RENTES, A. F.; NAZARENO, R. R.; SILVA, A. L. Mapeamento do Fluxo de Valor para Produtos com Ampla Gama de Peças. In: XXIII ENCONTRO NACIONAL DE ENGENHARIA DE PRODUÇÃO. Ouro Preto-MG, 2003.

ROTHER, M.; SHOOK, J. Learning to See. ValueStream Mapping to Create Value and Eliminate Muda. Cambridge, Massachusetts: The Lean Enterprise Institute, v.1.3, 2003.
SHINOHARA, I. New Production System: JIT Crossing Industry Boundaries. Productivity Press, 1988.

SILVA, A. L.; RENTES, A. F. Tornado o layout enxuto com base no conceito de mini fábricas de produção: um estudo de caso. In: XXII ENCONTRO NACIONAL DE ENGENHARIA DE PRODUÇÃO. Curitiba, PR, 2002.

SLACK, N., CHAMBERS, S., JOHNSTON, R. Administração da Produção. $2^{a}$ ed. SãoPaulo: Atlas, 2002.

WOMACK, J.P.; JONES, D.T. A Mentalidade Enxuta nas Empresas: elimine o desperdício e crie riqueza. $3^{a}$ reimpressão. Rio de Janeiro: Elsevier, 2004. 